\title{
Effect of implementing a mobile game on improving dietary information in diabetic patients
}

\author{
Zahra Koohmareh $^{1}$, Majid Karandish², Ali Mohammad Hadianfard ${ }^{2 *}$ (1)
}

Received: 9 Nov 2020

Published: 29 May 2021

\section{Abstract}

Background: Nowadays, digital games are not just entertainment, but beside routine treatments, they are used in patient care, especially in patients with diabetes. Application of digital games in patient's education can improve self-management of diabetes. The aim of the present study was to evaluate the effect of a mobile game (Amoo) implementation on enhancing dietary information in patients with type 2 diabetes.

Methods: A mobile game (called Amoo), which was developed by researchers of this study, was applied to assess the self-education of patients with diabetes. Sixty patients with type 2 diabetes participated in the study. The participants took part in a pre-intervention test to determine their dietary information. The participants were randomly divided into one of two groups, including the intervention group: played the game for 15 minutes daily for 6 weeks, and the control group: did not involve in the game. A post-intervention test was run to show a possible improvement in dietary information. Data were analyzed using paired t test and suitable non-parametric testes including Mann-Whitney and Wilcoxon signed rank tests as well as Spearman and Pearson correlation coefficients via IBM SPSS statistics version 21 (SPSS, v 21.0, IBM, Armonk, NY, USA). A P-value less than 0.05 was considered as a significant level.

Results: The results indicated a statistically significant difference between the pre and post test scores in the intervention group $(\mathrm{p}<0.001)$. However, there was no significant difference in fasting blood sugar $(\mathrm{p}=0.125)$.

Conclusion: The mobile game (Amoo) could enhance the knowledge of patients with type 2 diabetes about food calories and glycemic index. This means that mobile games may serve as an educational aid to these patients.

Keywords: Diabetes, Mobile Game, Education, Mobile-Health

Conflicts of Interest: None declared

Funding: Nutrition and Metabolic Disease Research Center, Ahvaz Jundishapur University of Medical Sciences, Ahvaz, Iran (grant no. NRC-9723)

*This work has been published under CC BY-NC-SA 1.0 license.

Copyright $\odot$ Iran University of Medical Sciences

Cite this article as: Koohmareh Z, Karandish M, Hadianfard AM. Effect of implementing a mobile game on improving dietary information in diabetic patients. Med J Islam Repub Iran. 2021 (29 May);35:68. https://doi.org/10.47176/mjiri.35.68

\section{Introduction}

In recent years, digital games are designed for specific purposes rather than pure entertainment. They are used extensively in the field of education, simulation, sport, and health (1). Digital games have been recommended as a potential tool for developing effective educational experiences (2).

The growing interest in the use of games and simulations is evidenced in the medical domain (3). Various

Corresponding author: Dr Ali Mohammad Hadianfard, hadianfard-a@ajums.ac.ir

1. Depatment of Health Information Technology, School of Allied Medical Science,Ahvaz Jundishapur University of Medical Sciences, Ahvaz, Iran

2. Nutrition and Metabolic Diseases Research Center, Ahvaz Jundishapur University of Medical Sciences, Ahvaz, Iran studies have established the potential of digital games to support health education (3-5). Simulated games can improve the acquisition and retention of clinical skills and the safety of patients (6). Nowadays, the internet and a wide range of mobile devices (i.e., mobile phones and tablets) are available to consumers. Digital games can play an important role in treating and educating patients, especially in chronic and non-communicable diseases such as

$\uparrow$ What is "already known" in this topic:

- Educational games are growing rapidly as a tool for treating patients.

- New theoretical models are emerging in the field of educational games for diabetic patients.

$\rightarrow$ What this article adds:

Amoo educational game, which is accompanied by intelligence, has been effective in educating calories and glycemic of food to type 2 diabetic patients. 
diabetes $(7,8)$.

Diabetes has remained the leading cause of death worldwide $(9,10)$. As well, diabetes has become the ninth leading cause of death in women and the 16th cause of death in Iranian men $(11,12)$. Digital games can be considered as an active learning method for teaching the basic concepts of diabetes to patients (13).

Studies have shown that the use of mobile technologies can improve the management of chronic noncommunicable diseases such as diabetes in middle-income countries $(14,15)$. Digital technology provides access to educational content, information, and general support for those with diabetes, the most challenging chronic disease with complex clinical care and management $(16,17)$. Educational programs are the basis for the treatment and prevention of diabetes (18). Furthermore, technologybased education can support regular diabetes selfmanagement activities including continuous glucose monitoring, physical exercise, healthy nutrition, taking medication, management of complications, and problemsolving (19).

Since the introduction of mobile technology, educational programs have been expanded for diabetic patients, and the management of patient health data such as glucose levels has been improved. For example, education through Short Message Service (SMS) resulted in improving glycemic control $(14,20)$.

Studies have shown that digital learning education is more effective than traditional educational approaches in increasing patients' knowledge (21). For example, a mobile game designed for diabetic children to improve dietary information showed that the game was attractive to children, so their knowledge about diet and healthy lifestyle was improved (22). Moreover, in another study, three digital games were designed to train nutrition and control calorie intake and were given to eight diabetic patients. The results showed that mobile games could be a new and promising approach to provide appropriate educational content (23).

In addition, digital educational games, compared with traditional training methods, can stablish communication among players, so patients can share the results of their game with others (24).

Studies have shown that game-based education is developing fast and is becoming a key tool in medical education (25). Therefore, researchers aim to promote a healthy lifestyle and global awareness using games and media in a fun and motivating fashion. However, few games on nutrition topics have been developed and have been shown to be successful in promoting physical activity and changing dietary behavior (26). The aim of the present study was to evaluate the effect of mobile gamebased learning apps on improving dietary information in patients with type 2 diabetes.

\section{Methods}

The present study is an interventional study conducted in southwestern Iran. In this study, the effect of an independent variable (mobile phone game) on the dependent variables (Amoo diabetic game test score, blood glucose level, the total amount of sugar and calories of foods) was investigated. The study was approved by the Ethics Committee of Ahvaz Jundishapur University of Medical Sciences with code: IR.AJUMS.REC.1397.909.

A total of 60 adult patients with type 2 diabetes who referred to Shahid Sadegh Ganji Specialty Clinic (Borazjan, Iran) were selected for the study. In calculating the sample size, $95 \%$ as confidence level and power of $85 \%$ were considered. The inclusion criteria were as follows: 1- adult patients (age $>18$ ), 2- minimum literacy, 3- confirmation of diabetes by a qualified specialist, 4- having an Androidpowered smartphone. 5- Ability to work with a smart phone, 6-Willingness to participate in the study. Exclusion criteria were as follows:1- Patients who have attended the center's self-care training classes. 2-Patients who have an underlying disease other than diabetes or taking nondiabetic medications. 3- Patients with more than 5 years of diabetes. 4- Android devices running on versions lower than 4.0.4, 5- smart phone annoying problems such as crashes and failed installation. 6- Unwillingness to participate in the study. Patients were given clear explanations in this trial and informed consent was obtained prior to data collection.

\section{Intervention}

Patients were randomly assigned into the intervention or control group ( $\mathrm{n}=30$ in each group). After randomization, the fasting blood sugar of all participants (both groups) was measured and recorded once before the intervention and again at the end of the intervention and, they took part in a pre-intervention test to determine their dietary information. The test was conducted in the presence of the researcher and in a condition where they were not allowed to talk to each other and to use the internet or any other accessories. Due to the nature of the intervention, the participants were not blinded. Therefore, the diabetic Amoo game was installed and implemented separately for the intervention group. The participants were trained on how to run the game by one member of the research team for an hour. The intervention group was asked to play the Amoo game 15 minutes per day for 6 weeks. It was monitored by a WhatsApp group to ensure that the participants played the game. The duration of gaming was determined by the researchers according to the level of the game and the results obtained from a pilot study. At the same time, the control group received educational content similar to the game through a brochure. During the study, all participants received the routine treatment of diabetes which was prescribed by the physician and no change or intervention was performed.

\section{Characteristics of the diabetic Amoo mobile game}

The diabetic Amoo mobile game, which is a noncommercial game, was developed by the researcher. In this prototype version, 14 foods (pineapple, grapes, cooked rice, oranges, eggs, corn, olives, potatoes, honey, kiwi, walnuts, fish, watermelon, and carrots) with different calorie and glycemic index were considered for training. The game was designed in two episodes and in Persian. The first episode includes the glycemic index diet 
components lists for nutrition education and the second episode contains the comprehensive guide for food calorie and glycemic index. Figure 1 shows the game start page. The process of the game is that the player is presented with three (low, medium, high) glycemic foods at the beginning of the game. Then, by starting the game, these three foods appear randomly in front of the player. The player must choose the 6 low glycemic foods that were initially displayed to him/her to complete the first episode and move on to the second episode. If the player chooses one or more of the not allowed foods, he/she must repeat the first episode. Figures 2 and 3 show the first episode of the game.

In the second episode, like the previous one, three foods with different glycemic-index diets and calories are displayed (Fig. 4). The player should select 15 lowglycemic and low-calories foods to fulfill the episode successfully. The game is supported by intelligent analysis, so the players' choices are analyzed accordingly. The game ends when the player has achieved a very good result.

\section{Characteristics of the diabetic Amoo test}

The test consisted of 16 questions. Two of them were yes or no questions that were not assigned a score but were included in the statistical tests. For the other 14 questions, a score of " 1 " was assigned to each correct answer and a score of " 0 " for each wrong answer. Therefore, a total score of 14 was considered. The questions were designed based on the Amoo diabetic training tips. Pre-test and post-test were administered at the same questions and same condition and all the participants (study /control) participated in the tests. In order to establish test security and minimize recall bias, questions and options were shifted accordingly.

Data (Age, sex, level of education, type of treatment, Amoo diabetic test scores, and fasting blood sugar level) were analyzed using descriptive statistics and IBM SPSS statistics version 21 (SPSS, v 21.0, IBM, Armonk, NY, USA). A P-value less than 0.05 was considered as a significant level.

Due to the lack of a normal assumption, the nonparametric Mann-Whitney test was used to compare the score of Amoo diabetic test, fasting blood sugar, and the level of sugar and food calories between both groups. Since the normal distribution was not established in the study group, the non-parametric Wilcoxon signed rank test was used before and after the intervention to compare the fasting blood sugar level and Amoo diabetic test scores. In the control group, paired $t$ test was used to compare the fasting blood sugar level before and after the intervention. Spearman and Pearson correlation coefficients were used to investigate the relationship among test scores, age, and education levels of participants.

\section{Results}

The sample size consisted of 32 females and 28 males. The intervention group included 14 males and 16 females with a mean age of 43.93 , and the control group com-

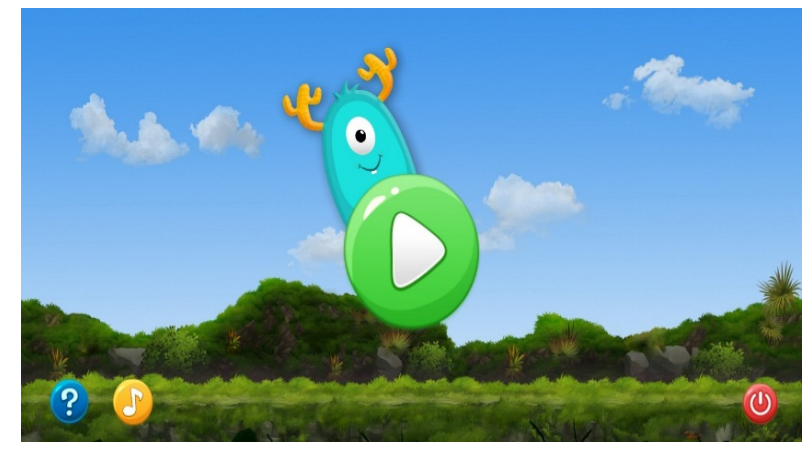

Fig. 1. Start page of the game

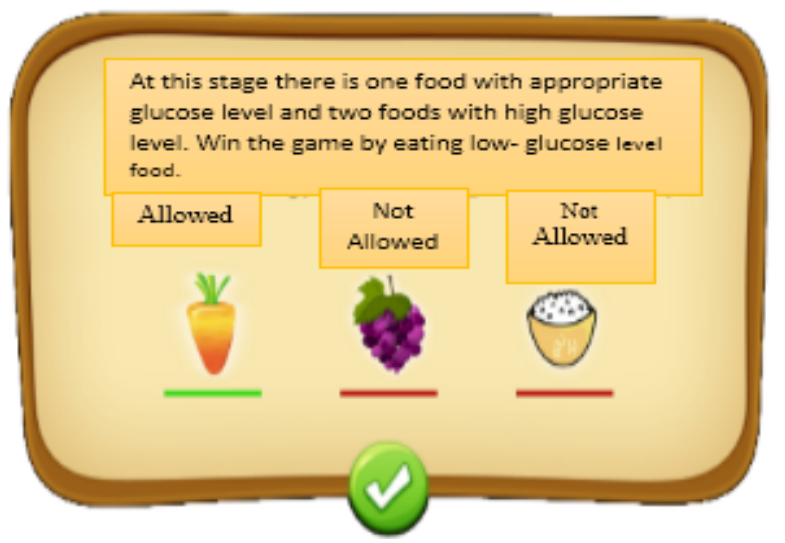

Fig. 2. Glycemic index training stage of the game

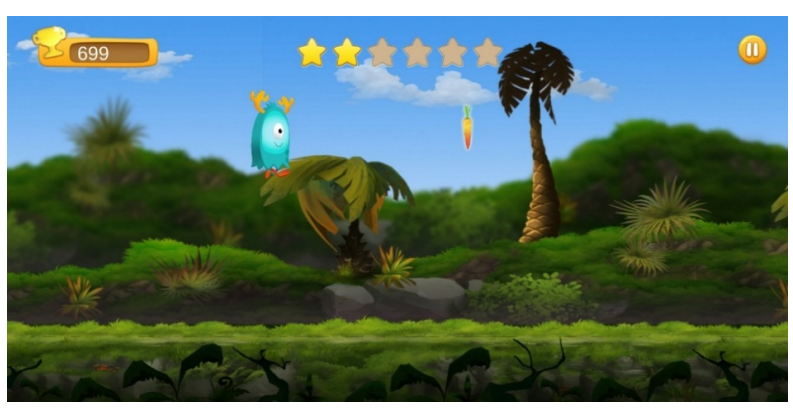

Fig. 3. The episode I of diabetic Amoo mobile game

Each food has different calories and glycemia.

Win the game by choosing the best food.

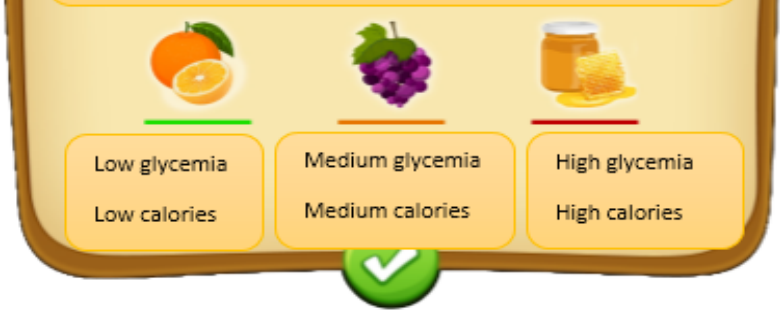

Fig. 4. Calories and glycemic index training stage (episode II) of the game

prised 14 males and 16 females with a mean age of 44.13 . There were no significant differences between the mean age of the two groups $(\mathrm{p}>0.05)$. The mean duration of diabetes was 32.20 and 39.83 in the intervention and con- 
trol groups, respectively. Therefore, there was no statistically significant difference between the groups $(\mathrm{p}=0.069)$ (Table 1).

The mean test score in the intervention group before the intervention was 7.27 and after the intervention was 12.63, and the mean test score in the control group before and after the intervention was 7.47 and 7.63, respectively. The mean fasting blood glucose in the intervention group before and after the intervention was 160.70 and 158.86 , respectively; and for the control group, the mean was 161.13 and 161.36, respectively (Table 2).

Before the intervention, the results of the independent samples t-test and Mann-Whitney test showed no statistically significant difference between the intervention and control groups in test score $(p=0.756)$ and fasting blood sugar $(\mathrm{p}=0.728)$. Similarly, no statistically significant difference was found between the two groups concerning the attention to fasting blood sugar $(\mathrm{p}=0.301)$ and food calories $(\mathrm{p}=0.580)$.

After the intervention, a statistically significant difference was found between the mean scores of the intervention group and the control group $(\mathrm{p}<0.001)$. However, no statistically significant difference was observed in the mean of fasting blood sugar between the intervention and control groups $(p=0.625)$. Concerning the effect of the intervention on attention to sugar and food calories in both groups, the difference was statistically significant $(\mathrm{p}<0.001)$ (Table 2).

In the intervention group, the results of the Wilcoxon signed rank test showed a statistically significant difference in the Amoo game test score before and after the intervention $(p<0.001)$, but in the control group, the difference was not statistically significant $(p=0.472)$.

After the intervention, all participants in the intervention group ( $n=30)$ chose the "yes" choice (yes-no option) for the two variables: attention to food glucose level foods and food calories. Although the tendency to choose the "yes" option after the intervention was evident. But, in the control group, there was no statistically significant difference before and after the intervention to compare attention to food glucose level $(\mathrm{p}>0.99)$ and calories $(\mathrm{p}=0.219)(\mathrm{Ta}-$ ble 2).

There was no significant correlation between education level and test scores before and after the intervention (Table 3); likewise, there was no correlation between age and test scores before and after the intervention (Table 4).

\begin{tabular}{|c|c|c|c|}
\hline Variable & Control group $(\mathrm{n}=30)$ & Intervention group $(\mathrm{n}=30)$ & $\mathrm{p}$ \\
\hline Gender; $\mathrm{n}(\%)$ & & & $>0.99^{*}$ \\
\hline Female & $16(53.3)$ & $16(53.3)$ & \\
\hline Male & $14(46.7)$ & $14(46.7)$ & \\
\hline Education level; n (\%) & & & $0.157^{* *}$ \\
\hline Up to Diploma Degree & $15(50.0)$ & $8(26.7)$ & \\
\hline Associate Degree & $6(20.0)$ & $7(23.3)$ & \\
\hline Bachelor's degree or higher & $9(30.0)$ & $15(50.0)$ & \\
\hline Type of treatment; $\mathrm{n}(\%)$ & & & $0.360^{*}$ \\
\hline medication & $21(70.0)$ & $25(83.3)$ & \\
\hline medication+ insulin & $9(30.0)$ & $5(16.7)$ & \\
\hline Age; Mean \pm SD & $44.13 \pm 7.91$ & $43.93 \pm 8.99$ & $0.927^{\circ}$ \\
\hline Duration of diabetes; Mean \pm SD & $39.83 \pm 22.98$ & $32.20 \pm 28.35$ & $0.069^{\epsilon}$ \\
\hline \multicolumn{4}{|c|}{ * Fisher's exact test; ${ }^{*} *$ Chi-square test; ${ }^{\circ}$ Independent Samples t-test; ${ }^{\epsilon}$ Mann-Whitney } \\
\hline \multicolumn{4}{|c|}{ Table 2. Comparison of the pre/post intervention outcomes in each group } \\
\hline Outcome & Control group $(\mathrm{n}=30)$ & Intervention group $(\mathrm{n}=30)$ & $\mathrm{p}$ \\
\hline \multicolumn{4}{|l|}{ Test score; Mean \pm SD } \\
\hline Before intervention & $7.47 \pm 2.36$ & $7.27 \pm 2.59$ & $0.756^{\circ}$ \\
\hline After intervention & $7.63 \pm 1.99$ & $12.63 \pm 1.13$ & $0.001^{\epsilon}<$ \\
\hline P-value & $0.472^{*}$ & $0.001^{*}<$ & \\
\hline \multicolumn{4}{|l|}{ Fasting blood sugar; Mean \pm SD } \\
\hline Before intervention & $161.13 \pm 31.85$ & $160.70 \pm 33.66$ & $0.728^{\epsilon}$ \\
\hline After intervention & $161.36 \pm 30.79$ & $158.86 \pm 33.11$ & $0.625^{\epsilon}$ \\
\hline P-value & $0.779^{*}$ & $0.125^{*}$ & \\
\hline \multicolumn{4}{|l|}{ Attention to food glucose level; n (\%) } \\
\hline Before intervention & & & $0.301^{£}$ \\
\hline Yes & $13(43.3)$ & $18(60.0)$ & \\
\hline no & $17(56.7)$ & $12(40.0)$ & \\
\hline After intervention & & & $0.001^{£}<$ \\
\hline Yes & $13(43.3)$ & $30(100)$ & \\
\hline no & $17(56.7)$ & 0 & \\
\hline P-value & $>0.99^{*}$ & $<0.001^{*}$ & \\
\hline \multicolumn{4}{|l|}{ Attention to food calorie counts; $\mathrm{n}(\%)$} \\
\hline Before intervention & & & $0.580^{£}$ \\
\hline Yes & $8(26.7)$ & $11(36.7)$ & \\
\hline no & $22(73.3)$ & $19(63.3)$ & \\
\hline After intervention & & & $0.001^{\mathrm{E}}<$ \\
\hline Yes & $12(40.0)$ & $30(100)$ & \\
\hline no & $18(60.0)$ & 0 & \\
\hline P-value & $0.219^{*}$ & $<0.001^{*}$ & \\
\hline
\end{tabular}

${ }^{*}$ MCNemar test; ${ }^{⿷}$ Fisher's exact test; ${ }^{\epsilon}$ Mann-Whitney; ${ }^{*}$ Wilcoxon; $;{ }^{\circ}$ Independent Samples t-test. 


\begin{tabular}{lcc}
\hline Education level and test score & Spearman correlation coefficient & $\mathrm{p}$ \\
\hline Before intervention & -0.009 & 0.945 \\
After intervention & 0.145 & 0.268 \\
\hline & & \\
\multicolumn{3}{l}{ Table 4. The relationship between test scores and age of the participants } \\
\hline Age and test score & Pearson correlation coefficient & $\mathrm{p}$ \\
\hline Before intervention & -0.142 & 0.281 \\
After intervention & -0.006 & 0.966 \\
\hline
\end{tabular}

\section{Discussion}

Amoo game was used in this study as an intervention tool is a mobile app designed in Persian to instruct patients with type 2 diabetes. The game focused on teaching calories and glycemic index of foods. This game runs well on smartphones with Android OS. It is estimated that by 2020 over 2.87 billion people worldwide will have access to a smartphone, so smartphone games are the best choice to meet myriads of people globally with at least one thing in common (27).

Data analysis from various studies showed that the primary knowledge of participants about calorie menu and glycemic-index diet was relatively low. Moreover, the nutrition knowledge of type 2 diabetic patients with routine aspects of diabetic care was not completely satisfactory, so a diabetes education program is essential to all people with diabetes and contributes noticeably to successful diabetes self-management $(28,29)$.

This study showed the success of the Amoo game in improving initial knowledge of food calorie and glycemic index in patients with type 2 diabetes. Similarly, other studies also showed positive effects of educational games in improving the awareness of diabetic children about healthy diet $(22,30)$. Additionally, self-care management has improved in children and adolescents with diabetes (31). Moreover, the results of previous similar studies have shown that using games for diabetes selfmanagement training can be enjoyable and have educational value $(32,33)$. These games have shown to be effective in promoting youth dietary pattern changes, insulin therapy, glycemic control, and physical activity, i.e., a kind of mobile game called INSULOT was developed to educate the effects of insulin dosage and carbohydrate intake on blood glucose levels (34-38).

The results of the present study showed no statistically significant difference in the fasting blood sugar levels between the intervention and control groups. The reason could be explained due to the study period, i.e., more accurate results can be obtained by increasing the duration of the study and measuring the average level of blood sugar over the past three months (HbAlc). A systematic review and meta-analysis study showed that game-based interventions had no effect on HbAlc standardized mean difference (39). However, in a study, the effect of online games on diabetes self-management education was examined and patients who were randomized to an online game showed constant and significant $\mathrm{HbAlc}$ improvements (36).

In this study, the learning process and gaming were monitored by researchers; however, the game can be ap- plied to a large extent beyond the limits of time and place. Therefore, the educational effect of the game can be more evident in real life rather than in a research project environment. Moreover, most evidence suggest that gaming can facilitate the transfer of knowledge and the learning process in real life $(40,41)$.

In the present study, it is assumed that the level of education and age all have a direct impact on game-based learning, but the results showed no significant relationship between baseline game scores and the level of education and age of participants. Therefore, the Amoo game was found to be appropriate for Adults with diabetes and different level of education. Additionally, the Amoo game provided a positive step towards combining the potential of new powerful interactive media in teaching and learning which was consistent with the results of the previous similar studies (42-44).

From the nutritional point of view, different tools can be used in order to improve the nutritional knowledge of patients with diabetes mellitus, including glycemic index and glycemic load. Both of them are useful and it seems that glycemic load may be a more comprehensive tool. In this study glycemic index was selected because it is a fundamental tool, but it is suggested that both tools be incorporated in future versions of the game.

\section{Study limitations}

The sample size and duration of the intervention should be noted as the limitations of the present study.

\section{Conclusion}

Mobile-based digital games improve the knowledge and skills concerning glycemic index dietary behavior change in patients with type 2 diabetes without affecting blood glucose levels.

\section{Acknowledgement}

The authors would like to express their deep gratitude to Mr. Moji for designing and running the Amoo diabetic game.

\section{Conflict of Interests}

The authors declare that they have no competing interests.

\section{References}

1. Göbel S, Hardy S, Wendel V, Mehm F, Steinmetz R, editors. Serious games for health: personalized exergames. Proceedings of the 18th ACM international conference on Multimedia; 2010.

2. Mayer RE. Computer games in education. Ann Rev Psychol. 
2019;70:531-49.

3. Graafland M, Schijven M. How serious games will improve healthcare. Digital Health: Springer; 2018. p. 139-57.

4. Haoran G, Bazakidi E, Zary N. Serious games in health professions education: review of trends and learning efficacy. Yearbook of medical informatics. 2019;28(1):240.

5. Chon S-H, Timmermann F, Dratsch T, Schuelper N, Plum P, Berlth F, et al. Serious games in surgical medical education: a virtual emergency department as a tool for teaching clinical reasoning to medical students. JMIR Serious Games. 2019;7(1):e13028.

6.Ziv SDS, Paul Root Wolpe, Amitai. Patient safety and simulationbased medical education. Med Teach. 2000;22(5):489-95.

7. Miller AS, Cafazzo JA, Seto E. A game plan: Gamification design principles in mHealth applications for chronic disease management. Health Inform J. 2016;22(2):184-93.

8. Bargen T, Zientz C, Haux R. Gamification for mHealth-A review of playful mobile healthcare. Integr Inf Technol Manag Qual Care. 2014;202:225.

9. Patterson D, editor Using Interactive 3D Game Play to Make Complex Medical Knowledge More Accessible. ICCS; 2014.

10. World Health Organization.WHO - Diabetes. World Health Organization WHO. [Accessed 2020-06-08].

11. Booya F, Bandarian F, Larijani B, Pajouhi M, Nooraei M, Lotfi J. Potential risk factors for diabetic neuropathy: a case control study. BMC Neurol. 2005;5(1):24

12. Ahmadi A, Hasanzadeh J, Rajaefard A. To determine the relative factors on hypertension in Kohrang, Chaharmahal \& Bakhtiari province, 2007. Iran J Epidemiol. 2008;4(2).

13. Telner D, Bujas-Bobanovic M, Chan D, Chester B, Marlow B, Meuser J, et al. Game-based versus traditional case-based learning: comparing effectiveness in stroke continuing medical education. Canad Fam Physic. 2010;56(9):e345-e51.

14. Peimani M, Rambod C, Omidvar M, Larijani B, GhodssiGhassemabadi R, Tootee A, et al. Effectiveness of short message service-based intervention (SMS) on self-care in type 2 diabetes: A feasibility study. Prim Care Diabetes. 2016;10(4):251-8.

15. Slater H, Campbell JM, Stinson JN, Burley MM, Briggs AM. End user and implementer experiences of mHealth technologies for noncommunicable chronic disease management in young adults: systematic review. J Med Int Res. 2017;19(12):e406

16. Sinclair KA, Makahi EK, Shea-Solatorio C, Yoshimura SR, Townsend CK, Kaholokula JK. Outcomes from a diabetes selfmanagement intervention for Native Hawaiians and Pacific People: partners in care. Ann Behav Med. 2013;45(1):24-32.

17. Holtz B, Lauckner C. Diabetes management via mobile phones: a systematic review. Telemedicine and e-Health. 2012;18(3):175-84.

18. Diabetology C. 2018 Guidelines on the management of diabetic Clin Diabetol. 2018;7(1):1-90.

19. BOND GE. Lessons learned from the implementation of a Webbased nursing intervention. Comput Inform Nurs. 2006;24(2):66-74.

20. Greenwood DA, Gee PM, Fatkin KJ, Peeples M. A systematic review of reviews evaluating technology-enabled diabetes selfmanagement education and support. J Diabetes Sci Technol. 2017;11(5):1015-27.

21. Huang Z, Semwal M, Lee SY, Tee M, Ong W, Tan WS, et al. Digital health professions education on diabetes management: systematic review by the Digital Health Education Collaboration. J Med Int Res. 2019;21(2):e12997.

22. Baghaei N, Nandigam D, Casey J, Direito A, Maddison R. Diabetic Mario: Designing and evaluating mobile games for diabetes education. Games Health J. 2016;5(4):270-8.

23. DeShazo J, Harris L, Turner A, Pratt W. Designing and remotely testing mobile diabetes video games. Journal of telemedicine and telecare. 2010;16(7):378-82

24. Boulos MNK, Gammon S, Dixon MC, MacRury SM, Fergusson MJ, Rodrigues FM, et al. Digital games for type 1 and type 2 diabetes: underpinning theory with three illustrative examples. JMIR Serious Games. 2015;3(1):e3.

25. Bigdeli S, Kaufman D. Digital games in medical education: Key terms, concepts, and definitions. Med J Islam Repub Iran. 2017;31:52.

26. Majumdar D, Koch PA, Lee Gray H, Contento IR, de Lourdes IslasRamos A, Fu D. Nutrition science and behavioral theories integrated in a serious game for adolescents. Simul Gaming. 2015;46(1):68-97.

27. Cha SS, Seo BK. Smartphone use and smartphone addiction in middle school students in Korea: Prevalence, social networking service, and game use. Health Psychol Open. 2018;5(1):2055102918755046.

28. Breen C, Ryan M, Gibney MJ, O'Shea D. Diabetes-related nutrition knowledge and dietary intake among adults with type 2 diabetes. $\mathrm{Br} \mathrm{J}$ Nutr. 2015;114(3):439-47.

29. Speight J, Bradley C. The ADKnowl: identifying knowledge deficits in diabetes care. Diabetic Med. 2001;18(8):626-33.

30. Calle-Bustos AM, Juan MC, García-García I, Abad F. An augmented reality game to support therapeutic education for children with diabetes. PloS One. 2017;12(9):e0184645.

31. Brown SJ, Lieberman DA, Gemeny B, Fan YC, Wilson D, Pasta D. Educational video game for juvenile diabetes: results of a controlled trial. Med Inform. 1997;22(1):77-89.

32. Lazem S, Webster M, Holmes W, Wolf M. Games and diabetes: a review investigating theoretical frameworks, evaluation methodologies, and opportunities for design grounded in learning theories. J Diabetes Sci Technol. 2016;10(2):447-52.

33. Schakel L, Veldhuijzen DS, Manai M, Beugen Sv, Vaart Rvd, Middendorp Hv, et al. Editor's choice: Optimizing healthy food preferences by serious gaming. Psychol Health. 2020;35(4):405-24.

34. Baranowski T, Baranowski J, Cullen KW, Marsh T, Islam N, Zakeri I, et al. Squire's Quest!: Dietary outcome evaluation of a multimedia game. Am J Prev Med. 2003;24(1):52-61.

35. Ebrahimpour F, Najafi M, Sadeghi N. The design and development of a computer game on insulin injection. Electron Physic. 2014;6(2):845

36. Kerfoot BP, Gagnon DR, McMahon GT, Orlander JD, Kurgansky KE, Conlin PR. A team-based online game improves blood glucose control in veterans with type 2 diabetes: a randomized controlled trial. Diabetes Care. 2017;40(9):1218-25.

37. Kempf K, Martin S. Autonomous exercise game use improves metabolic control and quality of life in type 2 diabetes patients-a randomized controlled trial. BMC Endocrine Disord. 2013;13(1):57.

38. Aoki N, Ohta S, Okada T, Oishi M, Fukui T. INSULOT: a cellular phone-based edutainment learning tool for children with type diabetes. Diabetes Care. 2005;28(3):760-

39. Christensen J, Valentiner LS, Petersen RJ, Langberg H. The effect of game-based interventions in rehabilitation of diabetics: a systematic review and meta-analysis. Telemed E-health. 2016;22(10):789-97.

40. Furió D, GonzáLez-Gancedo S, Juan M-C, Seguí I, Rando N. Evaluation of learning outcomes using an educational iPhone game vs. traditional game. Comput Educ. 2013;64:1-23.

41. Assaf M, Van Hillegersberg J, Spil T, Arikat N, editors. Teachers' perceptions about using serious games in formal education in Jordan: Possibilities and limitations. 2019 IEEE Global Engineering Education Conference (EDUCON); 2019: IEEE.

42. Adjedj J, Ducrocq G, Bouleti C, Reinhart L, Fabbro E, Elbez Y, et al. Medical student evaluation with a serious game compared to multiple choice questions assessment. JMIR Serious Games. 2017;5(2):e11.

43. Shorey $\mathrm{S}, \mathrm{Ng}$ ED. Evaluation of Mothers' Perceptions of a Technology-Based Supportive Educational Parenting Program (Part 2): Qualitative Study. J Med Int Res. 2019;21(2):e11065.

44. Eley CV, Young VL, Hayes CV, Verlander NQ, McNulty CAM. Young people's knowledge of antibiotics and vaccinations and increasing this knowledge through gaming: mixed-methods study using e-Bug. JMIR Serious Games. 2019;7(1):e10915. 